\title{
Relationship between Interannual Variations in Satellite-based Vegetation Index and ENSO Phase over Tropical Forests
}

\author{
Shin NAGAI", Kazuhito ICHII ${ }^{* *}$ and Hiroshi MORIMOTO* \\ * Division of Earth and Environmental Sciences, Graduate School of Environmental Studies, Nagoya University, \\ Nagoya, 464-8601 Japan \\ ** San Jose State University, San Jose, 95192, USA
}

\begin{abstract}
Carbon cycle of tropical ecosystems may respond from climate variations related to El Niño-Southern Oscillation (ENSO). Although models and atmospheric studies have demonstrated the relationship, few studies have been conducted using direct observations on large spatial scales. In the present study, the interannual variations associated with ENSO period in the satellite-based Normalized Difference Vegetation Index (NDVI) data over low latitudinal zones $\left(30^{\prime} \mathrm{N}\right.$ to $\left.30^{\circ} \mathrm{S}\right)$ from 1981 to 2000 were analyzed using Singular Spectrum Analysis (SSA), which is an effective method to extract the variations from short-term noisy time-series data.

The NDVI variations over tropical rainforest are characterized by a high proportion of variances explained by ENSO time-scale mode, although the original NDVI data also contained the seasonal variations. In addition, these variations show a high correlation with Southern Oscillation Index (SOI) variation.

We concluded that the long-term satellite observation also shows the impact of ENSO-related climate variations on terrestrial vegetation activities.
\end{abstract}

Key words: ENSO, Interannual variability, NDVI, Tropical forests

\section{Introduction}

The terrestrial biosphere plays an important role in the global carbon cycle through photosynthesis and respiration. Tropical rainforests are exceedingly important because they account for approximately $20 \%$ of the global terrestrial carbon and $30 \%$ of the global net primary production (Prentice et al., 2001). Atmospheric $\mathrm{CO}_{2}$ inversion studies suggest that tropical land ecosystems contributed most of the interannual changes in the global carbon balance, responding to climate variations such as El NiñoSouthern Oscillation (ENSO) (Bousquet et al., 2000). Terrestrial biogeochemical modeling studies show the responses of tropical ecosystems to recent climate variations, including ENSO, over tropical regions (e.g. Botta et al., 2002). Direct observation of the terrestrial carbon cycle on a large geographic scale is important but a challenging task, especially over tropical regions.

Analysis of a satellite-based vegetation index such as the Normalized Difference Vegetation Index (NDVI) has the benefit of direct observation of vegetation activities and productivities with a high spatio-temporal resolution. The variability of vegetation activities has been mainly analyzed in northern middle and high latitude areas (e.g. Zhou et al., 2001), and semiarid regions (e.g. Anyamba et al., 2002), however, tropical regions were not analyzed well. Previous global analysis of the vegetation index also failed to find responses to environmental changes of terrestrial plant activities over tropical rainforest regions because of (1) the short-term analysis (Schultz and Halpert, 1995; Los et al., 2001), and (2) the absence of a clear correlation with climate (Schultz and Halpert, 1995; Kawabata et al., 2001), possibly due to the poor quality of satellite data resulting from cloud contamination and orbital drifts. Asner et al., (2000) analyzed the variability in vegetation activities over the Amazon, however, temporal coverage of their analysis was short (1982-1993), and it focused only on the Amazon region. On the other hand, satellite-based terrestrial biogeochemical models revealed changes in terrestrial productivities over the tropics (e.g. Nemani et al. ,2003), however, these results were dependent on climate data sets. Therefore, satellite-based data analysis that is independent of climate data, is required to detect changes in vegetation activities.

In the present study, we examined the relationship of the interannual variations in vegetation activities and climate over low latitudinal zones $\left(30^{\circ} \mathrm{N}-30^{\circ} \mathrm{S}\right)$ using the time-series NDVI data derived from the Advanced Very High Resolution Radiometer (AVHRR) on the National Oceanic and Atmospheric Administration (NOAA) satellites. We adapted Singular Spectrum Analysis (SSA), which is a useful approach to extract the long periodicity oscillation from short-term noisy time-series data, to the NDVI data from 1981 to 2000 , and low frequency components (20-60 months for ENSO) were reconstructed. Then, we analyzed the relationship 
between the reconstructed NDVI and observed climate data such as the Southern Oscillation Index (SOI), temperature, precipitation, and incoming surface solar radiation, to test the hypothesis that the extracted timeseries is related to climate variations.

\section{Materials and Methods}

\subsection{Data sets}

The Pathfinder AVHRR Land (PAL) NDVI data set (James and Kalluri, 1994) for 1981 to 2000, was used in this analysis. Original data set has an $8 \mathrm{~km}$ spatial resolution and a monthly temporal resolution, and we converted into half-degree spatial resolution data by spatial averaging. We complemented the data in 1994, based on monthly average of other years, because data are influenced by remarkable sensor degradation and data from Septermber to December are missing. Although some corrections, such as for sensor degradation, Rayliegh scattering, ozone absorption, and cloud screening were already applied to the PAL data set, residual errors caused by stratospheric aerosol (eruption of Mt. El Chichon in 1982 and Mt. Pinatubo in 1991), the orbital drift remained, we did not apply further correction, because SSA partially removed the high frequency noises.

Several climate data sets were used to characterize NDVI variability. We assumed that vegetation responded to three climate factors, temperature, precipitation, and radiation (Nemani et al., 2003). The temperature data sets are from Climatic Research Unit (CRU) TS 2.0 data set (available at http://www.cru.uea.ac.uk/ timm/grid/CRU_TS_2_0.ht $\mathrm{ml})$. The precipitation data is from CPC Merged Analysis of Precipitation (CMAP) data set (Xie and Arkin, 1996). The incoming surface solar radiation data is from the NCEP reanalysis data set (Kalnay et al., 1996). All of the climate date are converted into a monthly time-resolution and half-degree spatial resolution. In addition, we used SOI data distributed by CRU (available at http://www.cru.uea.ac.uk/cru/ data/soi.htm (Ropelewski and Jones, 1987) to investigate the NDVI-ENSO relationship. We used all data from Jul. 1981 to Dec. 2000.

\subsection{Subject area}

Our subject area covers from $30^{\circ} \mathrm{N}$ to $30^{\circ} \mathrm{S}$ for all longitude, which includes the tropical rainforest region, savannas, semi-arid regions, and the deserts of South America, Africa, and Asia.

\subsection{Methods}

We assumed that the time-series NDVI and climate data sets contain several components of time-variation such as an increasing or decreasing linear trend, decadal variability, variations associated with the ENSO period, seasonal variation, intra-seasonal variation, and residual noises. We focused on the interannual NDVI variations (for approximately 2-5 years) possibly caused by ENSO. We assumed that the ENSO-related variability is a period of $20-60$ months
(Yasunari, 1985), and extracted corresponding components of ENSO from the time-series NDVI and climate data (except for SOI) using SSA after subtracting the mean. SSA can be used to extract a low frequency oscillation from a short noisy data set applying flexible filters (Ghil et al., 2002). The seasonal variations in the original data sets were not removed to allow an evaluation of the contributions from intra-annual and inter-annual variations. We estimated the periodicity of only the first 12 principal components to reconstruct the ENSO-related variability in the NDVI time-series and climate data sets, and then, analyzed the correlation between NDVI variation and SOI, and climate variations.

\section{Results and Discussion}

\subsection{Proportion of variance assumed by ENSO- related NDVI variability}

The proportion of variance explained by reconstructed ENSO-related variation was estimated. A higher proportion of variance over tropical rainforest regions, such as the Amazon, and southeastern Asia, was explained by the mode of low frequencies (20-60 months). Although NDVI timeseries over the tropics contain seasonal variation, interannual signals are also dominant in tropical rainforest regions.

\subsection{Correlation between the ENSO-related NDVI variability and SOI data}

The relationship of interannual variation in ENSOrelated NDVI variation and in SOI was examined to characterize the reconstructed NDVI time series. Figure 1 shows the correlation coefficient between the interannual variations in ENSO-associated NDVI time-series and in SOI data on a seasonal basis. We can see a high positive correlation with the SOI for tropical rainforests of the Amazon, and southeastern Asia, especially in the Dec.-Feb. periods.

\subsection{Relationship between the ENSO-related NDVI} variability and climate variations

Time variations in ENSO-related NDVI and climate for the selected tropical rainforest regions (Amazon and Asia) are shown in Fig. 2. Year-to-year variations in the NDVI time-series and climate parameters have good correlation in years of strong El Niño events, 1982/83 and 1997/98, except for 1991-95. The ENSOrelated variability in the NDVI time-series and precipitation is inclined to decrease and those in temperature and radiation tend to increase. By contrast, the years with a negative anomaly in temperature and radiation, 1984, 1996, and 1999, also correspond with positive NDVI, precipitation anomalies. Although Nemani et al. (2003) suggested that radiation is an important limiting factor for plant growth in tropical forests, our results show that NDVI has a negative correlation with incoming surface solar radiation and has a positive correlation with precipitation. One of the possible mechanisms of the correlation is that 
precipitation, which is negatively correlated with incoming surface solar radiation based on cloud amounts, limits vegetation growth over these regions. However, we should care the quality of NDVI and climate data sets and statistically-based method of our analysis alike. Further analyses are needed to confirm the mechanism of interannual changes in vegetation activities over tropical regions based on other independent methodologies, such as terrestrial ecosystem models.
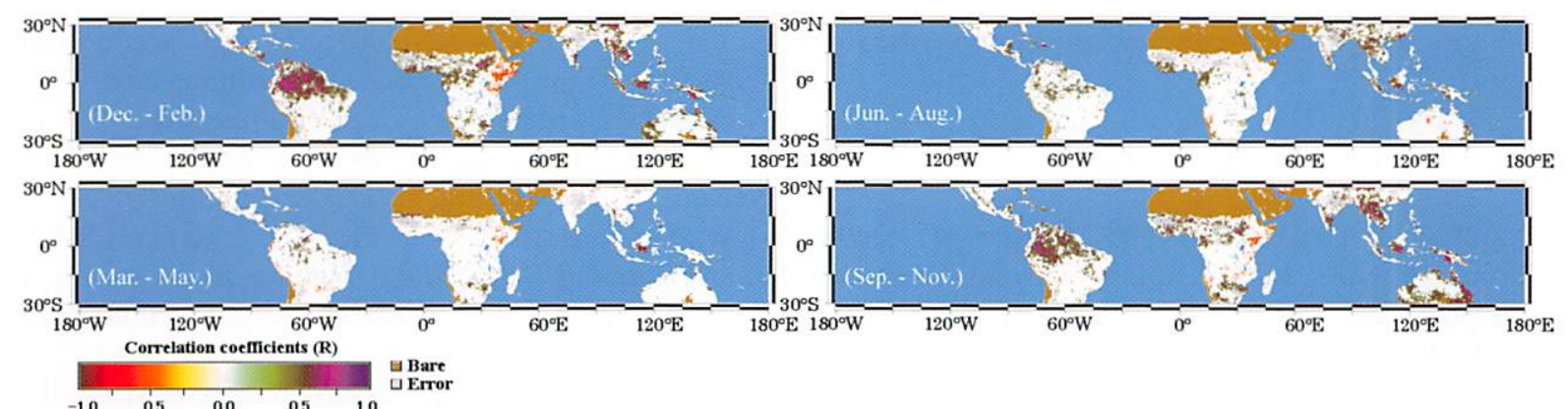

Fig. 1. Correlation between ENSO-related variability in the NDVI time-series and SOI in each season (Dec.-Feb., Mar.-May., Jun.-Aug., Sep.-Nov.). Areas with statistically significant correlation $(\mathrm{p}<0.05)$ are colored. We did not use the variations from December 1991 to November 1995 because of the effect of Mt. Pinatubo, the effect of the orbital drift on NDVI, and the effect of complemented NDVI time-series for 1994. A grid colored gray shows that it failed to calculate.

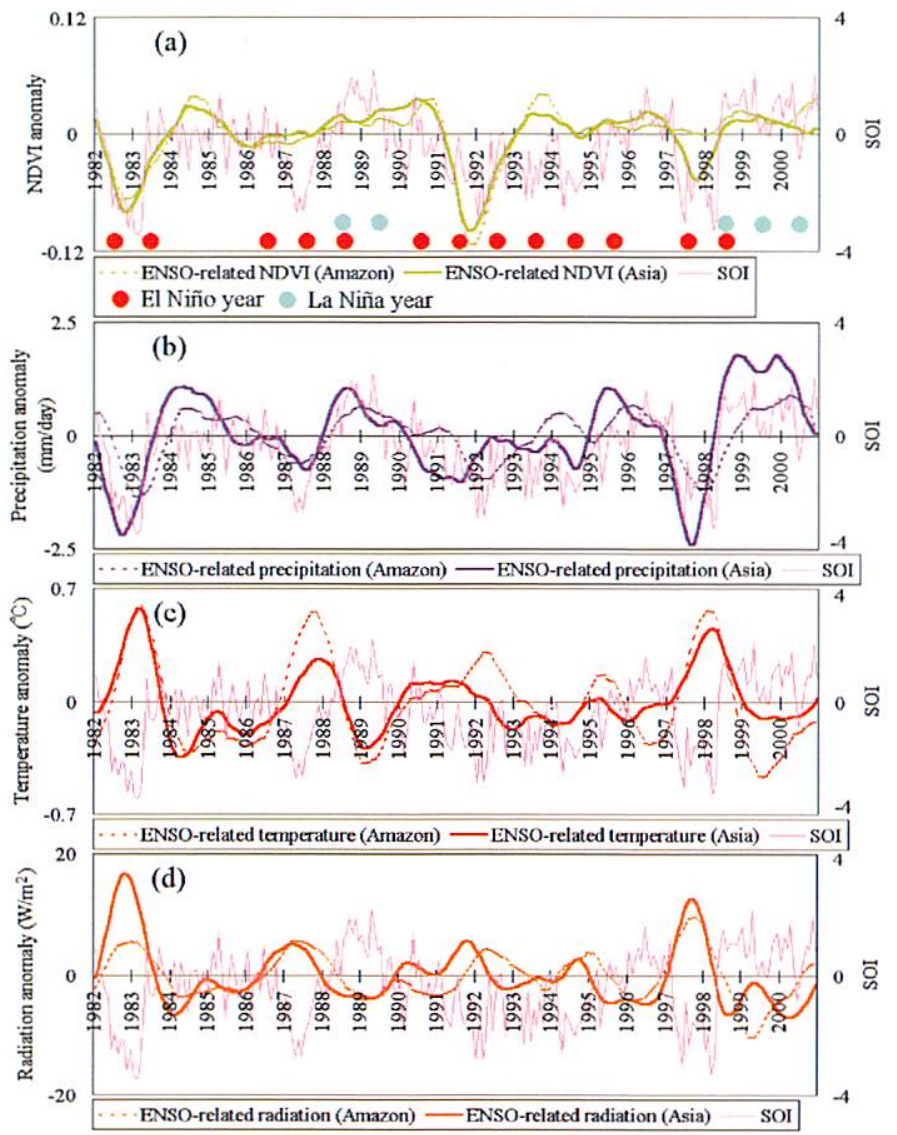

Fig. 2. Comparison between (a) extracted ENSO-associated NDVI (green line) and (b-d) extracted ENSO-related climate data (b: precipitation (blue line), c: temperature (red line), d: incoming surface solar radiation (orange line)) in the tropical rainforest of the Amazon $\left(30^{\circ} \mathrm{N}-30^{\circ} \mathrm{S}, 120^{\circ} \mathrm{W}-30^{\circ} \mathrm{W}\right.$, dotted line), and Asia $\left(30^{\circ} \mathrm{N}-30^{\circ} \mathrm{S}\right.$, $60^{\circ} \mathrm{E}-150^{\circ} \mathrm{E}$, solid line) from 1982 to 2000 . Moreover, the SOI time-series is shown by the pink solid line to mention the ENSO phase. Areas of evergreen broadleaf forests in the land cover map of DeFries et al. (1998) were defined as tropical rainforest in the analysis. The grids with statistically significant correlation of NDVISOI ( $<<0.05$, on a monthly basis) were used to average. 


\section{Acknowledgement}

This study was supported by a grant from the Ministry of Education, Culture, Sports, Science and Technology, Japan (Dynamics of the Sun-Earth-Life Interactive System, No.G-4, the 21 st Century COE Program) and the Takeda Techno-Entrepreneurship Award.

\section{References}

Anyamba, A., Tucker, C. J. and Mahoney, R., 2002: From El Niño to La Niña: vegetation response patterns over East and Southern Africa during the 1997-2000 period. J. Climate., 15, 3096-3103.

Asner, G. P., Townsend, A. R. and Braswell, B. H., 2000: Satellite observation of El Niño effects on Amazon forest phenology and productivity. Geophys. Res. Lett., 27, 981-984.

Botta, A., Ramankutty, N. and Foley, J. A., 2002: Long-term variations of climate and carbon fluxes over the Amazon basin. Geophys. Res. Lett., 29(9), doi: 10.1029/2001GL013607.

Bousquet, P., Peylin, P., Ciais, P., Le Quéré, C., Friedlingstein, P. and Tans, P. P., 2000: Regional changes in carbon dioxide fluxes of land and oceans since 1980. Science., 290, 1342-1346.

DeFries, R. S., Hansen, M., Townshend, J. R. G. and Sohlberg, R., 1998: Global land cover classifications at $8 \mathrm{~km}$ spatial resolution: the use of training data derived from Landsat imagery in decision tree classifiers. Int. J. Remote Sens., 19, 3141-3168.

Ghil, M., Allen, M. R., Dettinger, M. D., Ide, K., Kondrashov, D., Mann, M. E., Robertson, A. W., Saunders, A., Tian, Y., Varadi, F. and Yiou, P., 2002: Advanced spectral methods for climatic time series.Rev.Geophys.,40(1),doi:10.1029/2000RG 000092.

James, M. E. and Kalluri, S. N. V., 1994: The Pathfinder AVHRR land data set: an improved coarse-resolution data set for terrestrial monitoring. Int. J. Remote Sens., 15, 3347-3364.

Kalnay, E., Kanamitsu, M., Kistler, R., Collins, W., Deaven, D., Gandin, L., Iredell, M., Saha, S., White, G., Woollen, J., Zhu, Y., Chelliah, M., Ebisuzaki, W., Higgins, W., Janowiak, J., Mo, K. C., Ropelewski, C., Wang, J., Leetmaa, A., Reynolds, R., Jenne, R. and Joseph, D., 1996: The NCEP/NCAR 40-year reanalysis project. Bull. Am. Meteor. Soc., 77, 437-471.
Kawabata, A., Ichii, K. and Yamaguchi, Y., 2001: Global Monitoring of the interannual changes in vegetation activities using NDVI and its relationships to temperature and precipitation. Int. J. Remote Sens., 22, 1377-1382.

Los, S. O., Collatz, G. J., Bounoua, L., Sellers, P. J. and Tucker, C. J., 2001: Global interannual variations in sea surface temperature and land surface vegetation, air temperature, and precipitation. J. Climale., 14, 1535-1549.

Nemani, R. R., Keeling, C. D., Hashimoto, H., Jolly, W. M., Piper, S. C., Tucker, C. J., Myneni, R. B. and Running, S. W., 2003: Climate-driven increases in global terrestrial net primary production from 1982 to 1999. Science., 300, 1560-1563.

Prentice, I. C., Farquhar, G. D., Fasham, M. J. R., Goulden, M. L., Heimann, M., Jaramillo, V. J., Kheshgi, H. S., Le Quéré, C., Scholes, R. J. and Wallace, D. W. R., 2001: The carbon cycle and atmospheric carbon dioxide. In Climate change 2001: The Scientific Basis. Contribution of working group I to the third assessment report of the Intergovermental Panel on Climate Change (eds. by Houghton, J. T., Ding, Y., Griggs, D. J., Noguer, M., Linden, P. J., Dai, X., Maskell, K. and Johnson, C. A.). Cambridge University Press, Cambridge. United Kingdom \& New York. USA, pp.183-237.

Ropelewski, C. F. and Jones, P. D., 1987: An extension of the Tahiti-Darwin Southern Oscillation Index. Monthly Weather Review., 115, 2161-2165.

Schultz, P. A. and Halpert, M. S., 1995: Global analysis of the relationships among a vegetation index, precipitation and land surface temperature. Int. J. Remote Sens., 16, 2755-2777.

Xie, P. and Arkin, P. A., 1996: Analyses of global monthly precipitation using gauge observations, satellite estimates, and numerical model predictions. J. Climate., 9, 840-858.

Yasunari, T., 1985: Zonally propagating modes of the global east-west circulation associated with the Southern Oscillation. J. Meteor. Soc. Japan., 63, 1013-1029.

Zhou, L., Tucker, C. J., Kaufmann, R. K., Slayback, D., Shabanov, N. V. and Myneni, R. B., 2001: Variations in northern vegetation activity inferred from satellite data of vegetation index during 1981 to 1999. J. Geophys. Res., 106, 20069-20083. 